\title{
PERANCANGAN SISTEM INFORMASI PENILAIAN RAPORT SISWA BERBASIS WEB PADA SMA PERINTIS 1 SEPATAN
}

\author{
Harfizar $^{1}$ \\ Arief Saptono $^{2}$ \\ Bayu Dwi Kurniawan ${ }^{3}$ \\ Dosen STMIK Raharja ${ }^{1,2}$, STMIK Raharja Jurusan Sistem Informasi ${ }^{3}$ \\ Jl. Jendral Sudirman No. 40, Modernland, Tangerang \\ E-mail: harfizar@raharja.info ${ }^{1}$, arief.saptono@raharja.info ${ }^{2}$, bayu.dwi@raharja.info ${ }^{3}$
}

\begin{abstract}
ABSTRAK
Sistem penilaian raport pada SMA Perintis 1 Sepatan belum sepenuhnya terkomputerisasi. Permasalahan pada sistem yang berjalan saat ini yaitu dalam satu sekolah terdapat 143 siswa dan masing-masing mempunyai nilai yang berbeda-beda. Tak jarang penyimpanan nilai siswa dicatat dan disimpan secara konvensional, sehingga membutuhkan waktu yang sangat lama dalam pengerjaannya. Adapun tujuan dari penelitian ini adalah untuk memantau penilaian raport dengan menggunakan sistem berbasis web pada SMA Perintis 1 Sepatan. Untuk memenuhi kebutuhan sistem maka di butuhkan metode survey dan metode analisis elisitasi yang menghasilkan 33 butir fungsional dan dua butir non fungsional. Sedangkan rancangan model sistem ini menggunakan orientasi objek (Unified Modeling Language) dan implementasinya menggunakan bahasa pemograman PHP serta database MySQL. Dengan demikian sistem berbasis komputer ini dapat mempermudah dalam proses penilaian serta dapat dilakukan dengan cepat dan akurat.
\end{abstract}

\section{Kata kunci : Perancangan, Sistem Informasi, Penilaian Raport Siswa.}

\begin{abstract}
The assessment system report cards at Pioneer High School 1 Sepatan not been fully computerized. The problems in the current system is that in a school there are 143 students and each has a different value. Not infrequently storage student scores are recorded and stored in conventional, so it takes a very long time in the process. The purpose of this study was to monitor the appraisal report cards by using a web-based system at Pioneer High School 1 Sepatan. To meet the needs of the system in need of survey methods and analytical methods that yield 33 grains elicitation of functional and non-functional two grains. While the design of the models the system usesobject orientation (Unified Modeling Language)and implementation using PHP programming language and MYSQL database. Thus the computer-based system to facilitate the assessment process and can be done quickly and accurately.
\end{abstract}

Keywords: Design, Information Systems, Assessment of Student report cards. 


\section{PENDAHULUAN}

Berkat kemajuan teknologi komputer dan jaringan komunikasi data, sekarang internet dengan mudah dapat dinikmati dan dimanfaatkan sebagian besar masyarakat dunia, termasuk Indonesia. Internet sudah banyak diaplikasikan dalam berbagai bidang kehidupan dan tidak sedikit perubahan yang telah terjadi, salah satu perubahan yang sangat berpengaruh adalah lembaga pendidikan. Sekolah adalah salah satu contoh lembaga pendidikan yang terkena dampak dari kemajuan teknologi komputer. Salah satu bagian terpenting dari suatu sekolah adalah siswa dan nilai siswa tersebut. Tak jarang penyimpanan nilai siswa dicatat dan disimpan secara konvensional, sehingga membutuhkan waktu yang sangat lama dalam pengerjaannya. Contohnya pada sistem penilaian raport pada SMA Perintis 1 Sepatan belum sepenuhnya terkomputerisasi, petugas menerima berkas penilaian siswa dari setiap guru mata pelajaran lalu dicatat dalam buku kumpulan nilai dan menyalinnya kembali dalam raport lalu dibagikan ke wali/siswa. Tidak seditik wali/siswa yang tidak peduli dan ceroboh, hal inilah yang dikhawatirkan bisa menyebabkan raport hilang, basah, sobek dan hal-hal lainnya yang mengakibatkan kerusakan pada raport. Dengan demikian sistem penilaian raport berbasis komputer ini sangat diperlukan untuk dapat mempermudah dalam proses penilaian serta dapat dilakukan dengan cepat dan akurat.

\section{PERMASALAHAN}

1. Bagaimana sistem penilaian raport yang ada pada SMA Perintis 1 Sepatan?

2. Apa saja kendala yang terjadi pada sistem penilaian raport yang sedang berjalan pada SMA Perintis 1 Sepatan?

3. Bagaimana merancang sistem informasi penilaian raport yang diusulkan pada SMA Perintis 1 Sepatan?

\section{TINJAUAN PUSTAKA}

\section{Definisi Website}

Menurut Hidayat dalam Syukron (2015:29), "Website adalah kumpulan halamanhalaman yang digunakan untuk menampilkan informasi teks, gambar, diam atau gerak, animasi, suara, dan atau gabungan dari semuanya, baik yang bersifat statis maupun dinamis yang membentuk satu rangkaian bangunan yang saling terkait, yang masingmasing dihubungkan dengan jaringan-jaringan halaman".

\section{Definisi Unified Modelin Language (UML)}

Menurut Huda dalam R Plaza (2015:105), "Unified Modelin Language (UML) adalah sebuah "bahasa" yang telah menjadi standar dalam industri untuk visualisasi, merancang dan mendokumentasikan sistem peranti lunak. UML menawarkan sebuah standar untuk merancang model sebuah sistem".

\section{Literature Review}


Penelitian yang dilakukan Nursaid dkk (2015), menghasilkan sebuah sistem informasi yang dapat digunakan untuk penilaian hasil belajar. Penelitian ini diharapkan agar memberikan kemudahan dalam pelaksanaan kegiatan pengolahan nilai hasil belajar siswa yang dilakukan oleh bapak, ibu guru pengajar dan wali kelas. Metode yang digunakan dalam penelitian ini adalah observasi, wawancara, kepustakaan, analisis, perencanaan, perancangan atau desain, pembangunan, uji coba sistem serta implementasi sistem.[1]

Rivai dkk (2014) melakukan penelitian pada SMK Miftahul Huda Ngadirojo. Tujuan dari penelitian ini adalah mampu membangun sebuah Sistem informasi yang bisa dimanfaatkan oleh SMK Miftahul Huda Ngadirojo untuk membantu mengolah data nilai siswa dengan efektif. Untuk metodologi yang di gunakan yaitu studi lapangan, studi pustaka, perancangan, pembangunan, uji coba dan implementasi serta mengunakan metode SWOT. Hasil dari penelitian ini diharapkan bisa mendapatkan data-data yang akurat yang nantinya dapat mempermudah pengerjaan tugas akhir membangun Sistem informasi pengolahan data nilai siswa dan akhirnya sistem tersebut benar-benar bisa dimanfaatkan untuk mengelola nilai siswa dengan efektif.[2]

Tinjauan studi dari penelitian Surmalinda (2016). Penelitian ini bertujuan untuk menggantikan sistem perekapan nilai yang ada pada Madrasah Ibtidaiyah Islamiyah Ngrejeng Kabupaten Bojonegoro yang dulunya manual dapat menjadi terkomputerisasi dan kinerja menjadi lebih efisien dan dapat juga membantu kinerja dari pihak instansi tersebut. Adapun Metode yang digunakan dalam sistem informasi nilai siswa ini adalah SDLC (System 68 Development Life Cycle). Yang terdiri dari beberapa tahapan yaitu: identifikasi, analisis, desain, implementasi, testing, maintenance. Metodologi pengembangan yang digunakan adalah model PIECES. Dimana model PIECES merupakan urutan aktivitas yang dilakukan dalam pengembangan sistem mulai dari kinerja, ekonomi, keamanan aplikasi, efesiensi, dan pelayanan.[3]

Penelitian oleh Verawati dkk (2015), bertujuan memberikan gambaran tentang hasil implementasi sistem pengolahan data nilai siswa di SD Negeri 2 katekan yang telah berjalan selama satu semester. Proses analisis dilakukan menggunakan analisis PIECES dengan membandingkan proses pengolahan nilai sebelum penerapan sistem pengolahan data nilai dengan setelah diterapkannya sistem pengolahan data nilai siswa di SD Negeri 2 Katekan.[4]

Tinjauan studi pustaka penelitian Juhriah (2015) pada SMP Negeri 96 Jakarta, penelitian ini bertujuan untuk mempermudah bagi staff kurikulum maupun guru didalam mengelolah nilai serta bertujuan agar siswa, guru, walikelas serta user lain yang membutuhkan data nilai maupun data tentang siswa dapat diakses secara cepat dan efisien. 69 Metode penelitian adalah metode grounded (grounded search) yaitu suatu metode penelitian berdasarkan pada fakta dan menggunakan menetapkan konsep, membuktikan teori, mengembangkan teori.[5]

Penelitian yang dilakukan Anulika dkk (2014), bertujuan untuk memudahkan pengolahan hasil nilai siswa di sekolah menengah dan memiliki beberapa kelebihan seperti pengurangan biaya pengolahan pengurangan waktu yang dihabiskan dalam menghitung hasil nilai siswa serta lebih fleksibel dan dapat dimodifikasi sesuai jenis pencatatan dan pengolahan data. Peneliti menggunakan dengan menggunakan Adobe Dreamweaver, Integrated Development Environment, untuk menciptakan Graphic User Interface dan menulis kode, MYSQL (My Structured Query Language), sebuah 
Relational Database Management System (RDBMS) untuk membuat tabel database dan Rumah Pribadi halaman Pre-Processor (PHP), bahasa Scripting untuk berkomunikasi dengan dan memanipulasi database.[6]

Penelitian Takramah dkk (2015), Tujuan utamanya adalah untuk menerima proses dan menghasilkan laporan akurat dan setiap pengguna dapat mengakses sistem pada internet dengan fasilitas yang disediakan dan juga dimaksudkan untuk memberikan layanan yang lebih baik kepada pengguna, konsisten, dan tepat waktu data serta informasi yang efisien dengan mengubah proses kertas ke bentuk elektronik. Sistem ini dikembangkan menggunakan teknologi seperti PHP, HTML, CSS dan MySQL. PHP, HTML dan CSS digunakan untuk membangun user interface dan database yang dibangun menggunakan MySQL. Sistem ini bebas dari kesalahan dan sangat efisien dan kurang memakan waktu karena perawatan yang diambil untuk mengembangkannya.[7]

Tujuan penelitian yang dilakukan Llanda dkk (2016) ini untuk memenuhi kebutuhan spesifik dari registrar, instruktur dan siswa yang bisa memempersingkat waktu mereka, usaha dan untuk meningkatkan proses dan aliran dari sistem yang ada.metodologi pengembangan perangkat lunak yang digunakan yaitu PHP, JavaScript, CSS dan bahasa HTML scripting digunakan untuk sistem awal dan MySQL DBMS digunakan untuk 71 sistem akhir. Sistem ini dikembangkan ditemukan untuk dapat digunakan dalam hal yang efisiensi, mempengaruhi, menolong, kontrol, dan kemampuan belajar.[8]

Tinjauan studi pustaka penelitian Herman dkk (2013) yang dilakukan di University of Tabasco. Bertujuan untuk mengembangkan aplikasi agar siswa dapat berkonsultasi nilai dengan perangkat mobile pada Universitas Juarez Autonomous di Tabasco. Metodologi untuk mengembangkan layanan Web menggunakan SOHDM (Hypermedia Design Methodology Based on Object-Oriented Scenario) Metodologi ini melibatkan proses siklus dalam arti bahwa, dalam tahap tertentu kembali ke salah satu tahap sebelumnya dapat dilakukan untuk memperbaiki dan disesuaikan dengan kebutuhan yang muncul.[9]

Penelitian oleh Irfan (2012) menghasilkan perangkat lunak yang dapat mengelola data pribadi karyawan, data pribadi siswa dan data laporan hasil belajar siswa pada setiap semester dan setiap tahun dapat akses dari setiap waktu dan setiap tempat. Metode pengembangan perangkat lunak menggunakan Model Waterfall. 72 Software pengujian dilakukan melalui pengujian kotak putih dan kotak hitam, serta alpha dan beta melalui pengujian oleh sejumlah ahli dan pengguna. Hasil rancangan akhir menggunakan PHP dan MySQL untuk mengelola data pribadi karyawan, data pribadi siswa, dan laporan siswa hasil data belajar setiap semester dan setiap data tahun.[10]

\section{ANALISIS DAN PERANCANGAN SISTEM}

\section{Use Case Diagram}

Use Case Diagram menggambarkan fungsional yang diharapkan dari sebuah sistem yang dibangun. 


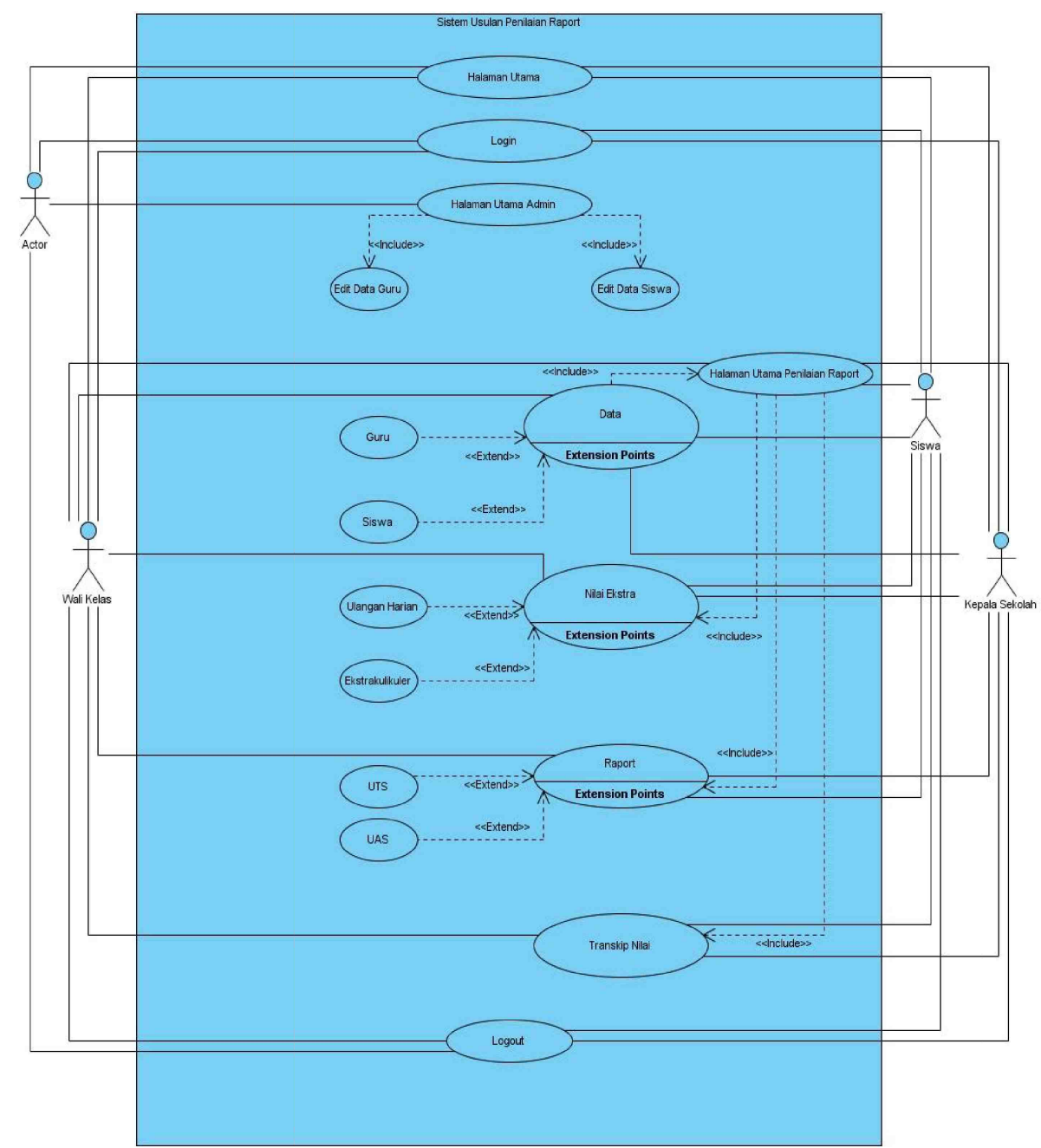

Gambar 1. Use Case Diagram

Berdasarkan gambar 4.1 use case diagram terdiri atas:

1. Satu sistem yang mencakup kegiatan sistem penilaian raport siswa

2. Terdapat empat aktor yang melakukan kegiatan didalam sistem, yaitu admin, walikelas, kepala sekolah dan siswa.

3. Terdapat lima use case yang dapat dilakukan aktor tersebur yaitu halaman utama, login, halaman utama admin, halaman utama penilaian raport dan logout.

4. Terdapat 12 include, yaitu edit data guru, edit data siswa, data, guru, siswa, nilai ekstra, ulangan harian, ekstrakulikuler, raport, UTS, UAS dan transkip nilai.

Prosedur sistemnya adalah sebagai berikut:

\section{Admin}
a. Melakukan login sistem
b. Menampilkan menu beranda
c. Melakukan akses sistem 
d. Melakukan penginputan data siswa dan data guru

e. Melihat data nilai ulangan harian, data nilai UTS dan data nilai UAS

f. Melakukan logout

2. Wali Kelas

a. Melakukan login sistem

b. Menampilkan menu beranda

c. Melakukan akses sistem

d. Melakukan penginputan data nilai ulangan harian, data nilai UTS dan data nilai UAS

e. Melihat data siswa dan data guru

f. Melakukan logout

\section{Siswa/Wali Murid}

a. Melakukan login sistem

b. Menampilkan menu beranda

c. Melakukan akses sistem

d. Melihat data siswa, data guru, data nilai ulangan harian, data nilai UTS dan data nilai UAS

e. Melakukan logout

\section{Class Diagram}

Class diagram merupakan diagram yang menjelaskan hubungan antar class dalam sebuah sistem yang sedang dibuat dan bagaimana caranya agar mereka saling berkolaborasi untuk mencapai tujuan. Berikut adalah class diagram perancangan sistem SMA Perintis 1 Sepatan : 


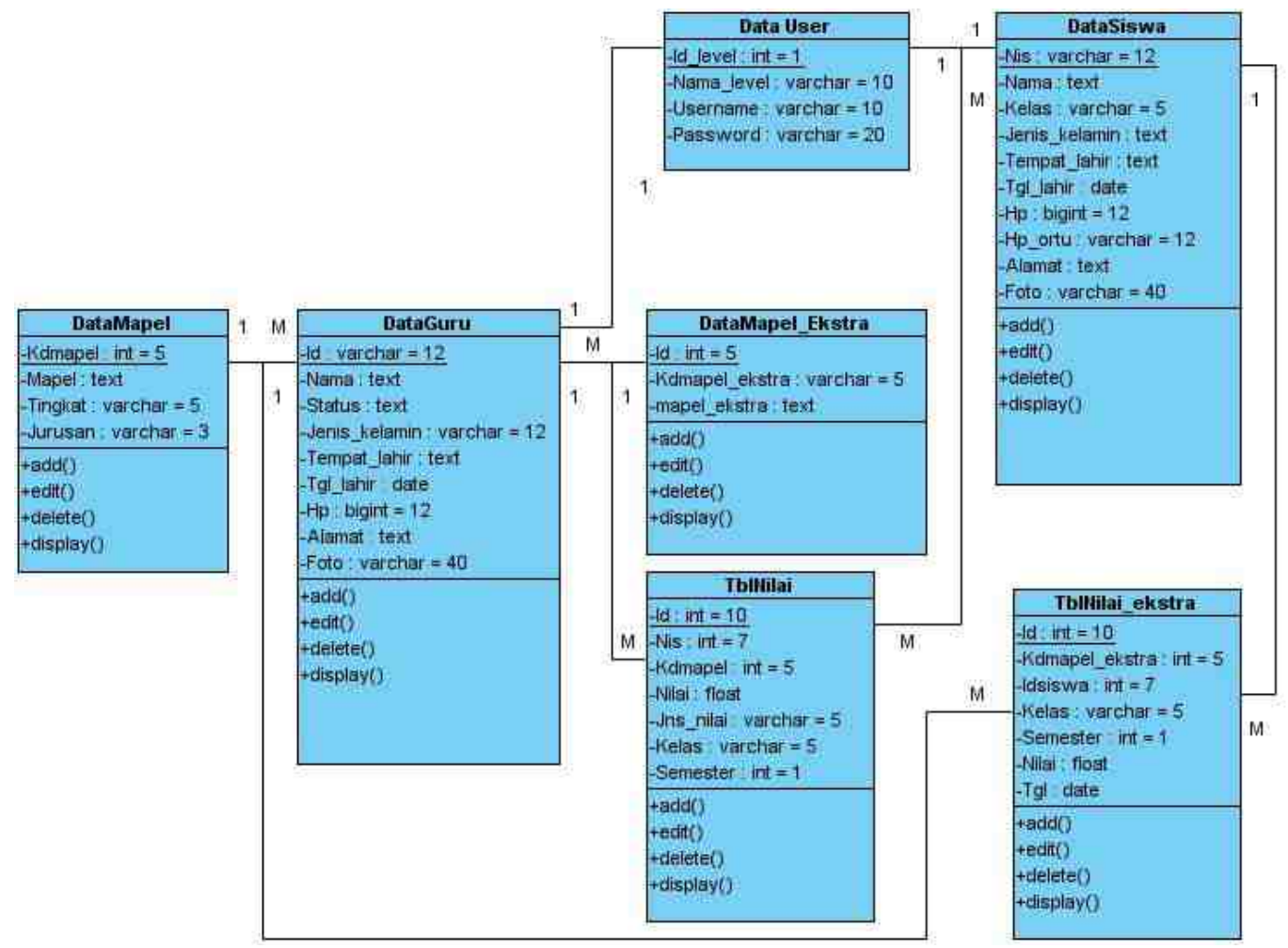

Gambar 2. Class Diagram

Keterangan:

1. Terdapat 7 class yaitu : datauser, datasiswa, dataguru, datamapel, datamapel_ekstra, tbnilai, dan tbnilai_ekstra.

2. Terdapat 8 association, yaitu relasi yang menghubungkan antar class.

\section{Struktur Database}

a. Tabel User

Primary Key : Id_level

Tabel 1.1. Tabel User

\begin{tabular}{|c|c|c|c|}
\hline No & Nama Field & Tipe Data & Nulls \\
\hline 1 & Id_level & $\operatorname{Int}(1)$ & - \\
\hline 2 & Nama_level & $\operatorname{Varchar}(10)$ & - \\
\hline 3 & Username & $\operatorname{Varchar}(10)$ & - \\
\hline 4 & Password & Varchar(20) & - \\
\hline
\end{tabular}

b. Tabel Guru

Primary Key : id 
Tabel 1.2. Tabel Guru

\begin{tabular}{|c|c|c|c|}
\hline No & Nama Field & Tipe Data & Nulls \\
\hline 1 & id & Varchar(12) & - \\
\hline 2 & Nama & Text & - \\
\hline 3 & Status & Text & - \\
\hline 4 & Jenis_kelamin & Varchar(12) & - \\
\hline 5 & Tempat_lahir & Text & - \\
\hline 6 & Tgl_lahir & Date & - \\
\hline 7 & Hp & Bigint(12) & - \\
\hline 8 & Alamat & Text & - \\
\hline 9 & Foto & Varchar(4) & - \\
\hline
\end{tabular}

c. Tabel Siswa

Primary Key : Nis

Tabel 1.3. Tabel Siswa

\begin{tabular}{|c|c|c|c|}
\hline No & Nama Field & Tipe Data & Nulls \\
\hline 1 & Nis & Varchar(12) & - \\
\hline 2 & Nama & Text & - \\
\hline 3 & Kelas & Text & - \\
\hline 4 & Jenis_kelamin & Varchar(12) & - \\
\hline 5 & Tempat_lahir & Text & - \\
\hline 6 & Tgl_lahir & Date & - \\
\hline 7 & Hp & Bigint(12) & - \\
\hline 8 & Hp_ortu & Bigint(12) & - \\
\hline 9 & Alamat & Text & - \\
\hline 10 & Foto & Varchar(4) & - \\
\hline
\end{tabular}


d. Tabel Mapel

Primary key : Kdmapel

Tabel 1.4. Tabel Mapel

\begin{tabular}{|c|c|c|c|}
\hline No & Nama Field & Tipe Data & Nulls \\
\hline 1 & Kdmapel & $\operatorname{Int}(5)$ & - \\
\hline 2 & Mapel & Text & - \\
\hline 3 & Tingkat & $\operatorname{Varchar}(5)$ & - \\
\hline 4 & Jurusan & $\operatorname{Varchar}(3)$ & - \\
\hline
\end{tabular}

e. Tabel Mapel Ekstra

Primary Key : id

Tabel 1.5. Tabel Mapel Ekstra

\begin{tabular}{|c|c|c|c|}
\hline No & Nama Field & Tipe Data & Nulls \\
\hline 1 & id & $\operatorname{Int}(5)$ & - \\
\hline 2 & kdmapel_ekstra & Varchar(5) & - \\
\hline 3 & Maple_ekstra & Text & - \\
\hline
\end{tabular}

f. Tabel Nilai

Primary Key : id

Tabel 1.6. Tabel Nilai

\begin{tabular}{|c|c|c|c|}
\hline No & Nama Field & Tipe Data & Nulls \\
\hline 1 & id & $\operatorname{Int}(10)$ & - \\
\hline 2 & Nis & $\operatorname{Int}(7)$ & - \\
\hline 3 & Kd_mapel & $\operatorname{Int}(5)$ & - \\
\hline 4 & Nilai & Float & - \\
\hline 5 & Jns_nilai & Varchar(5) & - \\
\hline 6 & Kelas & Varchar(5) & - \\
\hline 7 & Semester & $\operatorname{Int}(1)$ & - \\
\hline
\end{tabular}


g. Tabel Nilai Ekstra

Primary Key : id

Tabel 1.7. Tabel Nilai Ekstra

\begin{tabular}{|c|c|c|c|}
\hline No & Nama Field & Tipe Data & Nulls \\
\hline 1 & Id & $\operatorname{Int}(10)$ & - \\
\hline 2 & Nis & $\operatorname{Int}(7)$ & - \\
\hline 3 & Kdmapel_ekstra & $\operatorname{Int}(5)$ & - \\
\hline 4 & Nilai & Float & - \\
\hline 5 & Semester & $\operatorname{Int}(1)$ & - \\
\hline 6 & Kelas & Varchar(5) & - \\
\hline 7 & Tgl & Date & - \\
\hline
\end{tabular}

\section{IMPLEMENTASI}

\section{a. Halaman Utama}

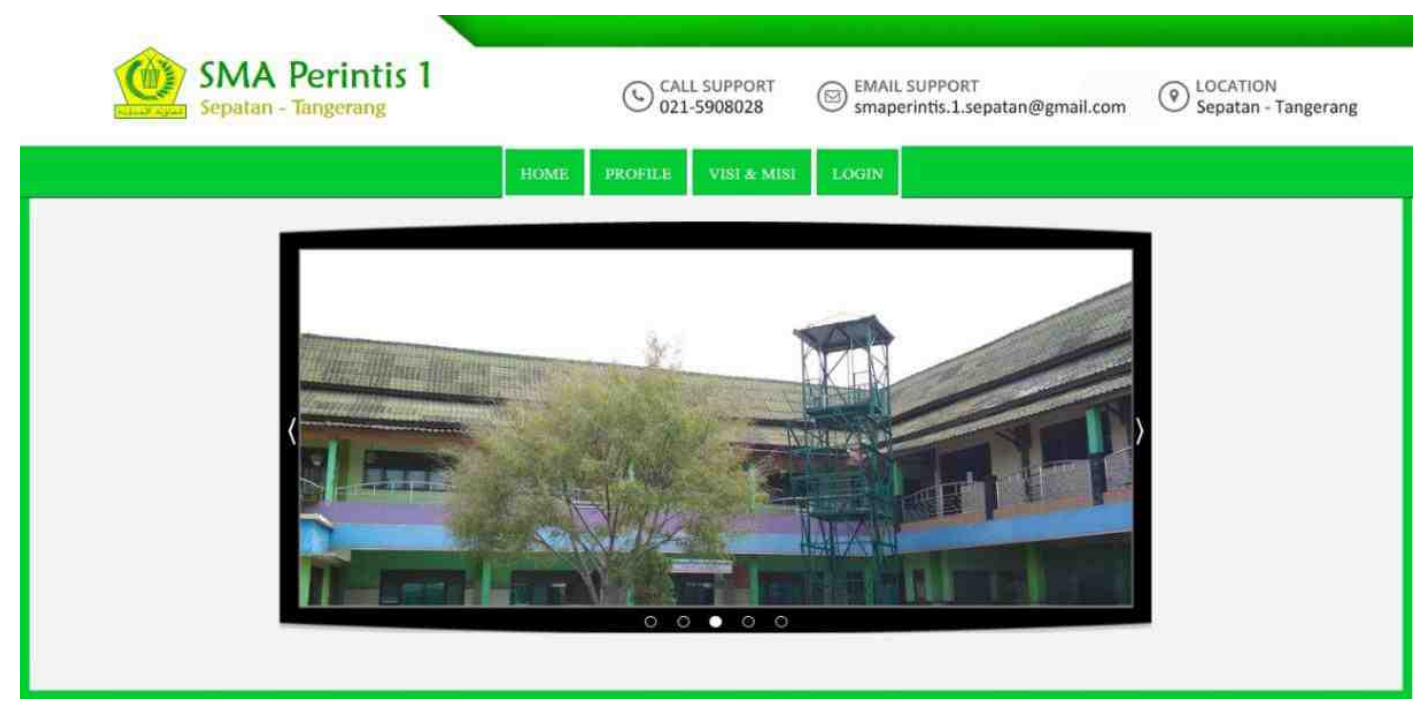

Gambar 3. Halaman Utama

Halaman ini berisi slide foto-foto sarana dan prasarana SMA Perintis 1 Sepatan, serta hal-hal mengenai SMA Perintis 1 Sepatan. 


\section{b. Login}

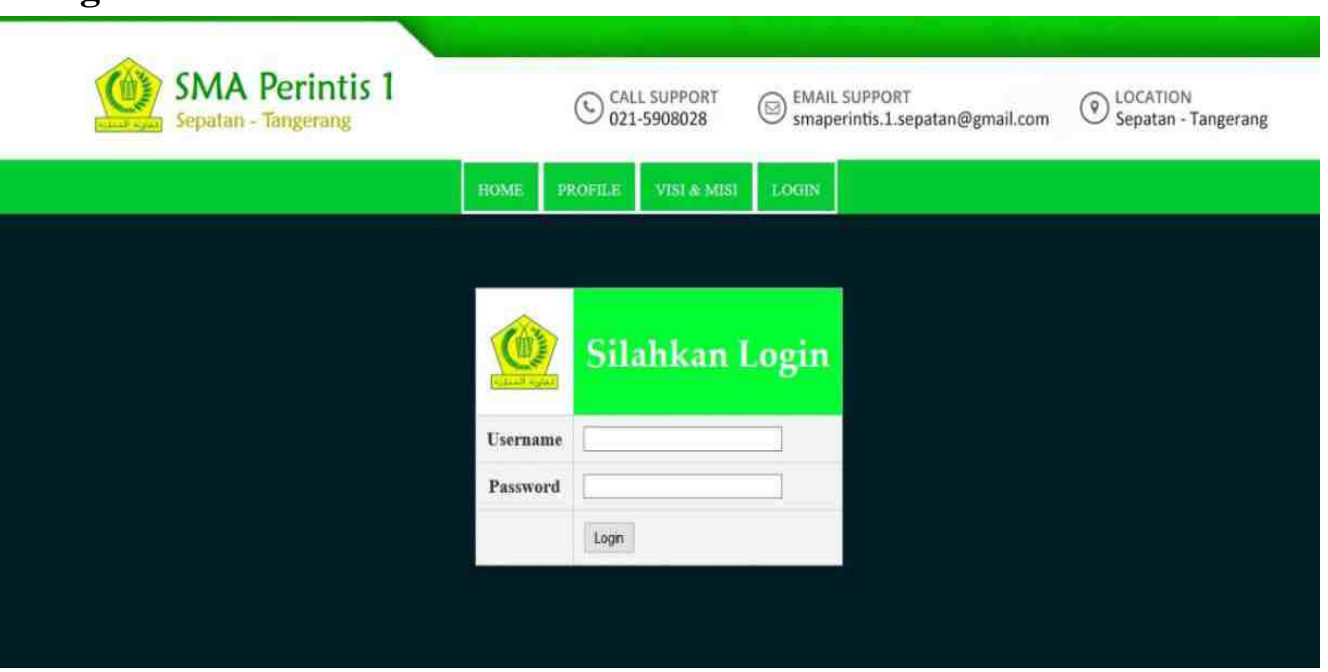

Gambar 4. Login

Berisikan halaman untuk login sesuai dengan username/password yang telah terdaftar.

c. Tampilan Admin Data Guru

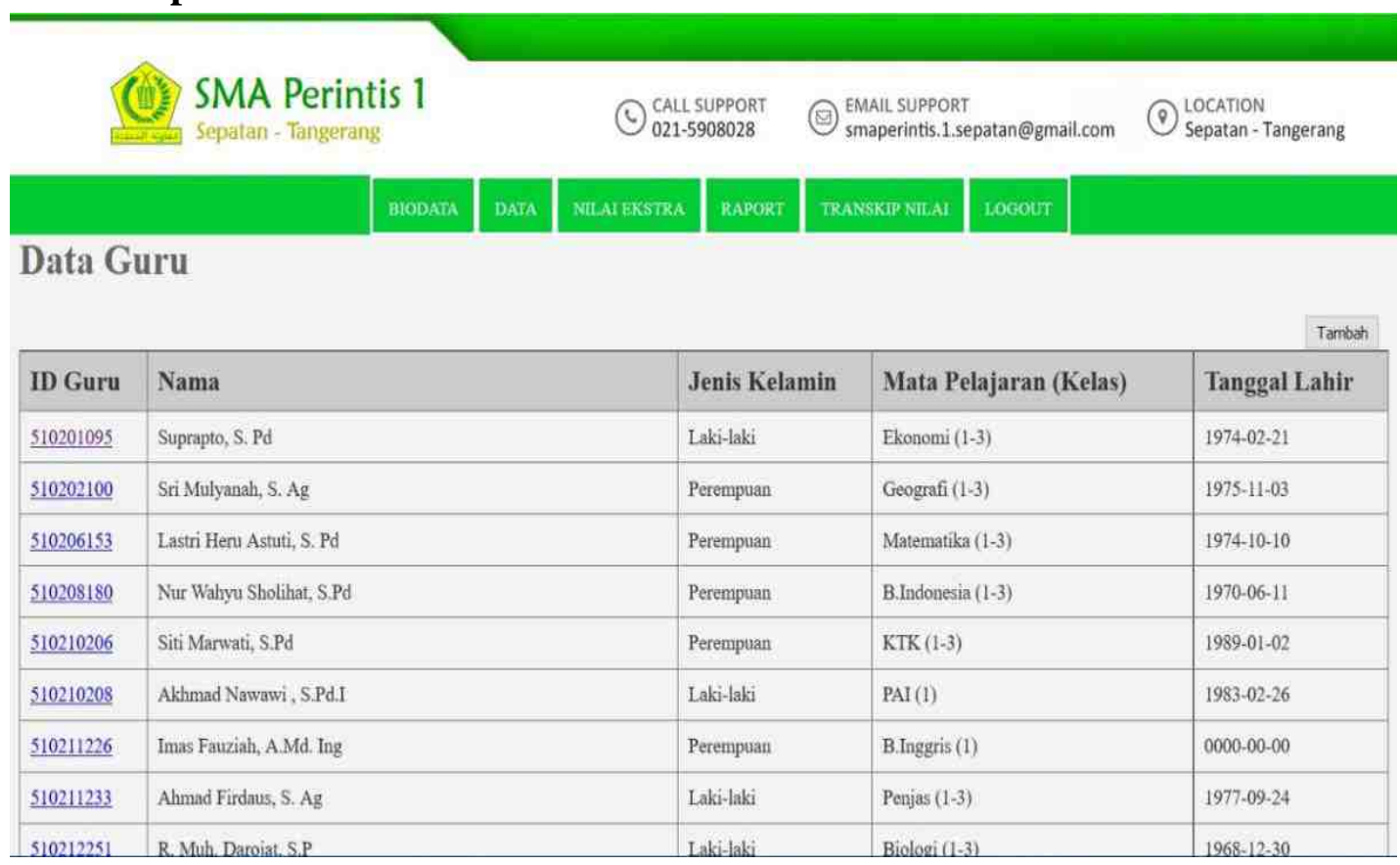

Gambar 5. Menu Data Guru

Halaman untuk admin yang berisikan data guru pada SMA Perintis 1. 


\section{d. Tampilan Admin Input Data Guru}

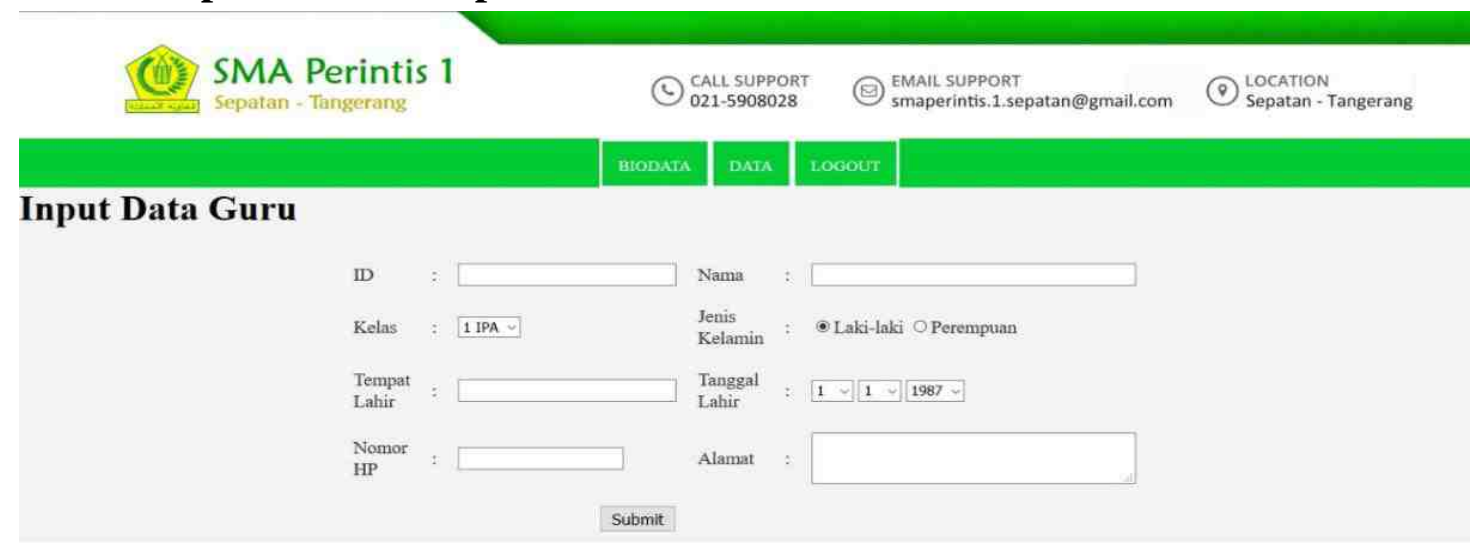

Gambar 6. Input Data Guru

Halaman untuk admin menginput data guru yang baru.

\section{e. Tampilan Admin Menu Data Siswa}

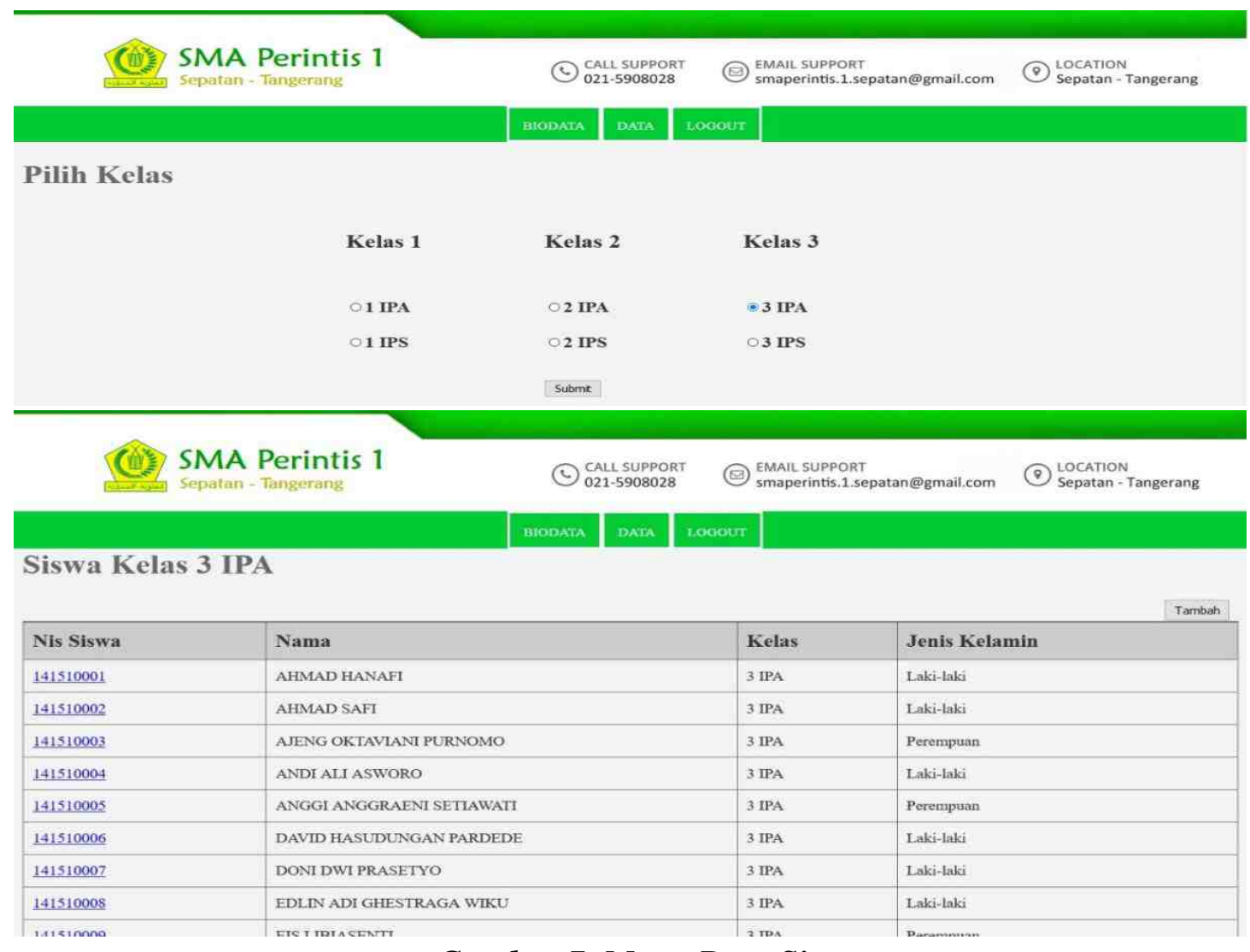

Gambar 7. Menu Data Siswa

Tampilan admin untuk melihat daftar siswa SMA Sepatan 1. 


\section{f. Tampilan Admin Input Data Siswa}

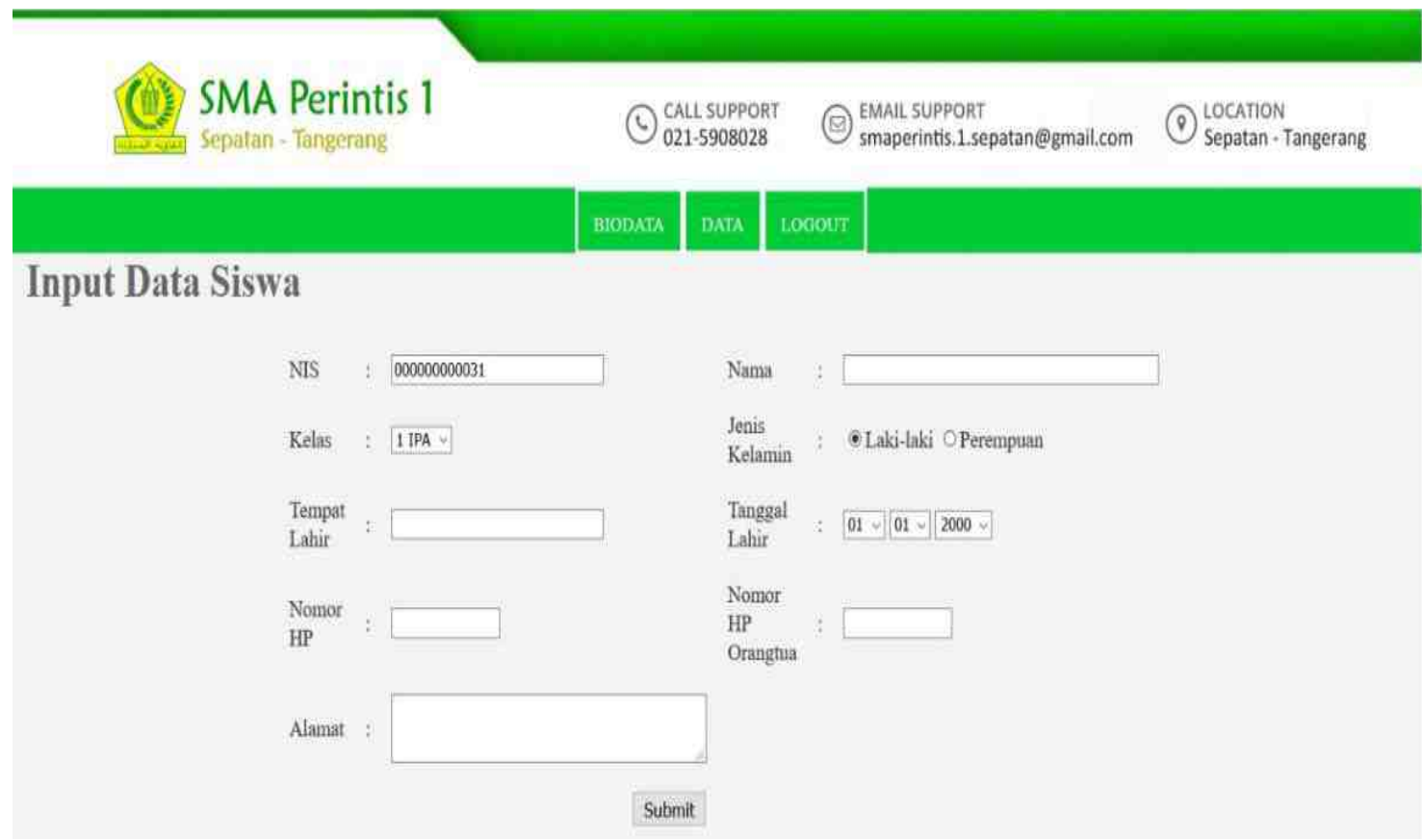

Gambar 8. Input Data Siswa

Tampilan admin untuk menginput data siswa baru.

\section{g. Tampilan Walikelas Input Nilai}

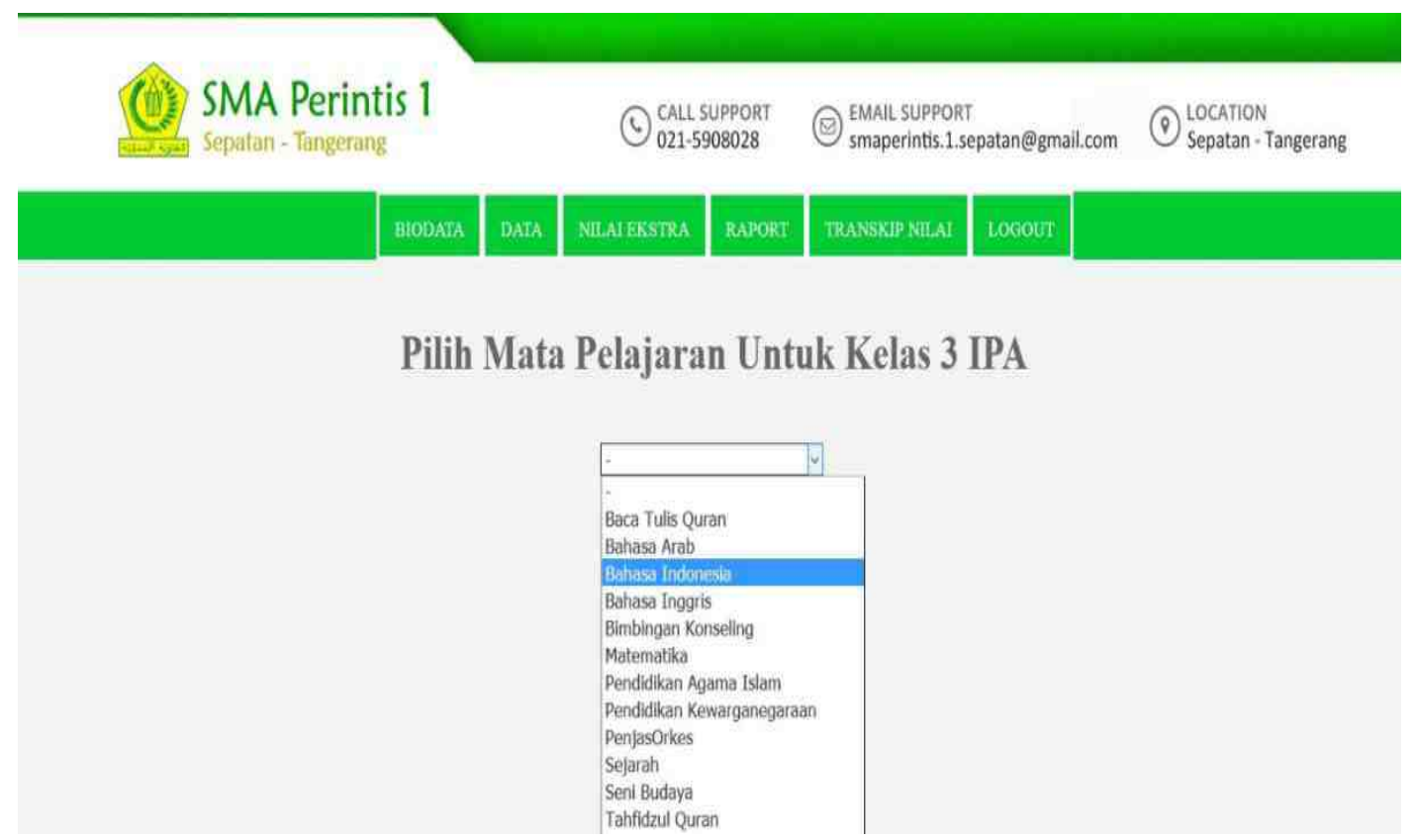




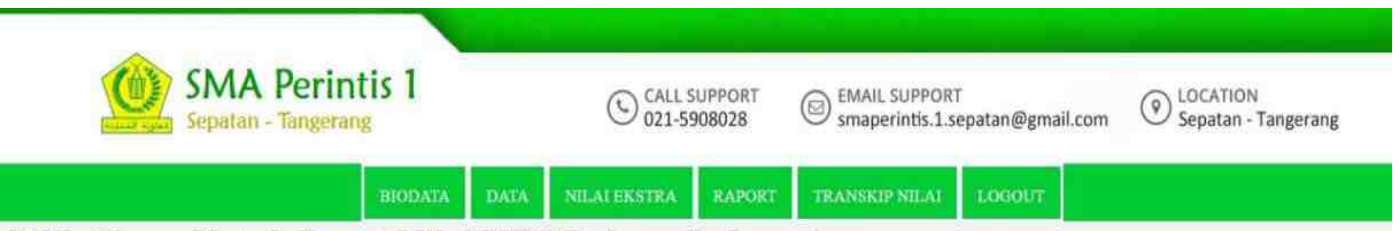

Pilih Siswa Untuk Input Nilai UTS Bahasa Indonesia

\begin{tabular}{|l|l|l|l|}
\hline Nis Siswa & Nama & Kelas & Jenis Kelamin \\
\hline 141510001 & AHMAD HANAFI & 3 IPA & Laki-laki \\
\hline 141510002 & AHMAD SAFI & 3 IPA & Laki-laki \\
\hline$\underline{141510003}$ & AJENG OKTAVIANI PURNOMO & 3 IPA & Perempuan \\
\hline$\underline{141510004}$ & ANDI ALI ASWORO & 3 IPA & Laki-laki \\
\hline$\underline{141510005}$ & ANGGI ANGGRAENI SETIAWATI & 3 IPA & Perempuan \\
\hline$\underline{141510006}$ & DAVID HASUDUNGAN PARDEDE & 3 IPA & Laki-laki \\
\hline$\underline{141510007}$ & DONI DWI PRASETYO & 3 IPA & Laki-laki \\
\hline$\underline{141510008}$ & EDLIN ADI GHESTRAGA WIKU & 3 IPA & Laki-laki \\
\hline$\underline{141510009}$ & EISLIBIASENTI & 3 IPA & Perempuan \\
\hline & & & \\
\hline
\end{tabular}

\section{SMA Perintis 1}

Sepatan - Tangerang

\section{(6) CALL SUPPORT}

021.5908028
() EMAIL SUPPORT

smaperintis.1.sepatan@gmail.com

(Q) LOCATION Sepatan-Tangerang

\section{\begin{tabular}{|l|l|l|l|l|}
\hline BIODATA & DATA & NIIAIEKSTRA \\
\hline
\end{tabular}}

Input Nilai UTS

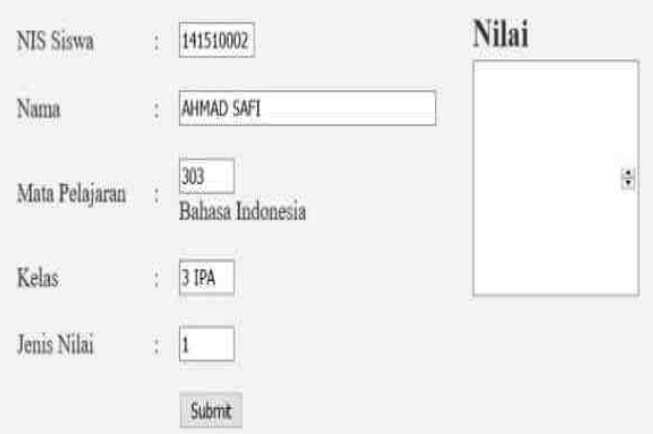

Gambar 9. Walikelas Input Nilai

Tampilan proses walikelas untuk menginput nilai siswa. 


\section{h. Menu Transkip Nilai}

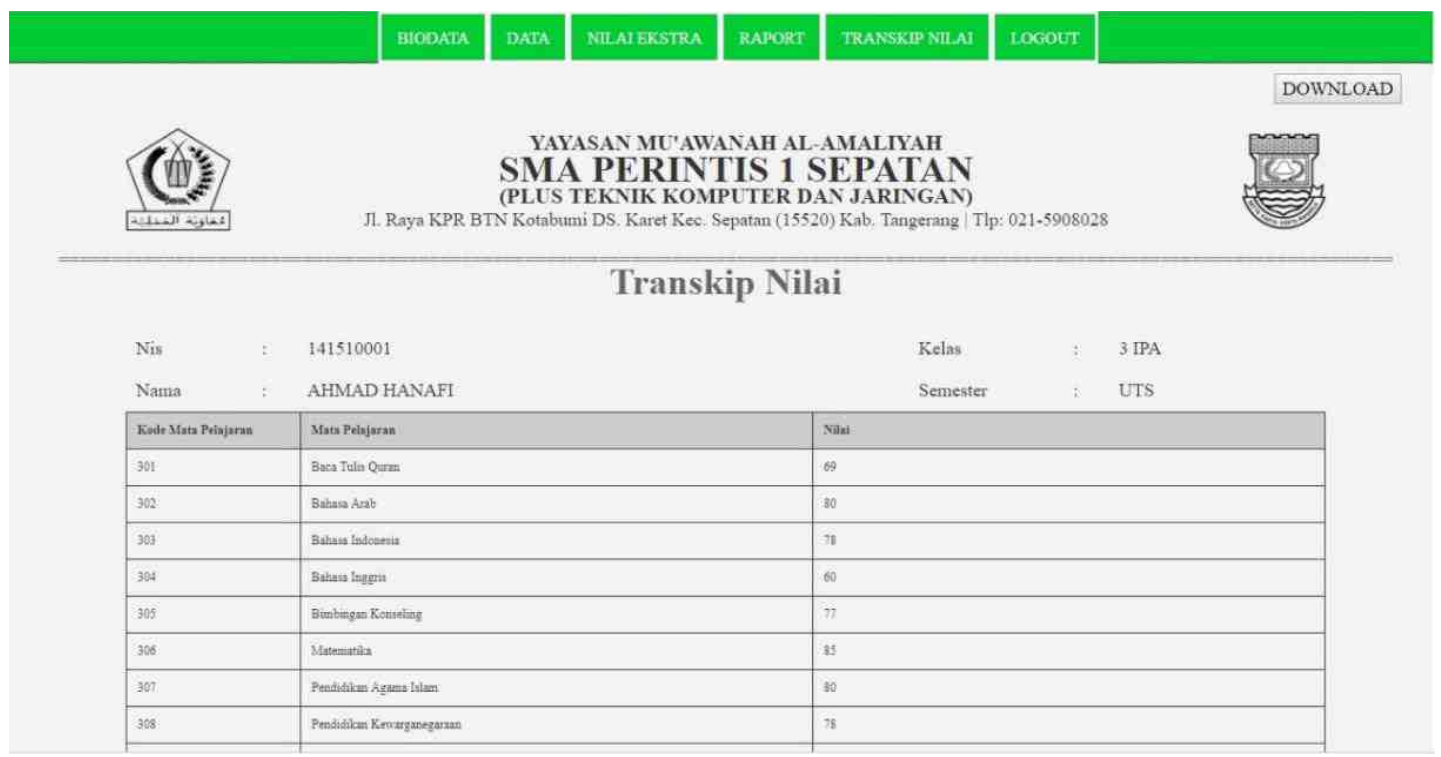

Gambar 10. Menu Transkip Nilai

Tampilan transkip keseluruhan nilai dari kelas 1 sampai Lulus.

\section{KESIMPULAN}

Berdasarkan dari hasi penelitian dan pengamatan yang telah dilakukan, maka dapat disimpulkan beberapa hal sebagai berikut:

1. Sistem penilaian raport yang berjalan saat ini di SMA Perintis 1 Sepatan belum sepenuhnya terkomputerisasi. Mekanisme kerjanya adalah menerima berkas penilaian 143 siswa dari setiap guru mata pelajaran setelah itu dicatat dalam buku kumpulan nilai dan menyalinnya kembali dalam satu buku yang disebut dengan raport. Setelah penyalinan tersebut raport disimpan dan dibagikan kepada setiap wali murid pada waktu penyerahan raport berlangsung. Dalam jangka waktu yang ditentukan oleh pihak sekolah, siswa diminta untuk mengembalikan raport tersebut kepada guru wali setiap kelas.

2. Kendala dalam penilaian raport yang berjalan saat ini di SMA Perintis 1 Sepatan adalah adanya 143 siswa dan masing-masing mempunyai nilai yang berbeda-beda, sehingga membutuhkan waktu yang sangat lama dalam pengerjaannya. Tak jarang penyimpanan nilai siswa dicatat dan disimpan secara konvensional oleh para guru.

3. Dalam merancang sistem informasi penilaian raport siswa yang diusulkan, peneliti menggunakan orientasi objek (Unified Modeling Language) dan implementasinya menggunakan bahasa pemograman PHP serta database MySQL 


\section{SARAN}

Dalam penerapan sistem yang berjalan, penulis ingin mengemukakan saran-saran agar sistem bisa berjalan dengan baik, diantaranya:

1. Merancang sistem penilaian raport berbasis website agar dapat membantu kinerja guru dalam penginputan nilai serta membantu orangtua siswa dalam memantau nilai putra/i-nya di sekolah.

2. Dalam penerapan sistem penilaian raport siswa, sebaiknya didukung oleh perangkat yang memadai, baik dari segi peralatannya (software dan hardware) maupun sumber daya manusia agar sistem dapat berjalan secara maksimal.

3. Apabila sistem yang baru sudah berjalan, perlu diperhatikan dan dilakukan evaluasi secara berkala terhadap sistem, untuk selanjutnya diadakan perbaikan sesuai perubahan dan perkembangan pada SMA Perintis 1 Sepatan.

\section{DAFTAR PUSTAKA}

[1] Nursaid, Berliana Kusuma Riasti dan Bambang Eka Purnama. 2015. "Pembangunan Sistem Informasi Penilaian Hasil Belajar Siswa pada SMA Negeri 2 Rembang berbasis Web”. Surakarta: IJNS APMMI (Asosiasi Profesi Multimedia Indonesia Surakarta). Vol.4 No.2.

[2] Rivai, Dani Ainur, dan Bambang Eka Purnama. 2014. "Pembangunan Sistem Informasi Pengolahan Data Nilai Siswa Berbasis Web pada SMK Miftahul Huda Ngadirojo". Surakarta: IJNS APMMI (Asosiasi Profesi Multimedia Indonesia Surakarta) Vol.3 No.2:20.

[3] Surmalinda, Sri. 2016. "Rancang Bangun Sistem Informasi Nilai Siswa pada Madrasah Ibtidaiyah Islamiyah Ngrejeng Kabupaten Bojonegoro". Surakarta: Jurnal Informa Politeknik Indonusa Surakarta. Vol. 1 No.3.

[4] Verawati, Ike dan Aullya Rachmawati. 2015. "Analisis Implementasi Sistem Pengolahan Data Nilai Siswa SD Negeri 2 Katekan”. Yogyakarta: Jurnal Semnasteknomedia Universitas Amikom Yogyakarta Vol.3 No.1.

[5] Juhriah, Een. 2015. "Perancangan Sistem Informasi Hasil Penilaian Siswa di Smp Negeri 96 Jakarta Berbasis Web". Jakarta: Journal Lppmunindra Universitas Indraprasta PGRI Tahun 2015.

[6] Anulika, Ezenma A., Emmanuel Bala dan Choji D. Nyap. 2014. "Design and Implementation of Result Processing System for Public Secondary Schools in Nigeria". Nigeria: International Journal of Computer and Information Technology Vol.3 No.1.

[7] Takramah, Wisdom Kwami dan Wisdom Kwasi Atiwoto. 2015. "Student Database System for Higher Education: A Case Study at School of Public Health, University of Ghana". Ghana: American Journal of Software Engineering and Applications Vol.4 No.2

[8] Llanda, Christopher John R., Janelyn A. Ambre dan Excel Philip B. Guiding. 2016. “Assist Web-Based Grade Entry and Inquiry System”. Philipina: Scholars Journal of Engineering and Technology Vol.4 No.4.

[9] Herman, Aguilar M., Hernandez T. Jose, Gomez M. Jorge, dan Contreras M. Andres. 2013. "Grade Query System Using Mobile Devices for Students of the Juarez Autonomous 
University of Tabasco". London: Proceeding of the World congress on Engineering Vol.2.

[10] Irfan, Rahmatul. 2012. "Assessment of Student Result Information System Design in Vocational High School". Yogyakarta : Eprints UNY International Conference on Vacational Education an Training (ICVET).

[11] Syukron, Akhmad dan Noor Hasan. 2015. "Perancangan Sistem Informasi Rawat Jalan Berbasis Web Pada Puskesmas Winong". Yogyakarta: Jurnal Bianglala Informatika AMIK BSI Yogyakarta. Vol.3 No.1:29.

[12] R Plaza, M. Abu Jihad, 2015. "Sistem Informasi Perpustakaan di SMP Negeri 12 Kotabumi Berbasis Borland Delphi 7". Lampung: Jurnal Informatika STMIK Surya Intan Kotabumi Lampung Utara. Vol.15 No.2:105. 